\title{
$\mathrm{Fe}_{2} \mathrm{O}_{3}-\mathrm{Al}_{2} \mathrm{O}_{3}$ 触媒上でのアンモニアによる 一酸化窒素の還元反応機構 ${ }^{122}$
}

(1975 年 4 月 26 日 受理)

新山浩雄・大川 朝 裕・越後谷悦郎*

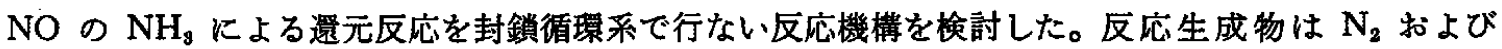
$\mathrm{N}_{2} \mathrm{O}$ であった。生成した $\mathrm{N}_{2}, \mathrm{~N}_{2} \mathrm{O}$ の窒素源を明らかにする目的で ${ }^{15} \mathrm{~N}$ でラベルした $\overline{\mathrm{N}}_{3}$ を用いた。 反応は以下に述べる実験結果 1)〜3）により次式で示すような逐次機構で進行すると結論された。

$$
\begin{aligned}
& \mathrm{NO}+\mathrm{NH}_{3} \longrightarrow \mathrm{N}_{2}+\mathrm{H}_{2} \mathrm{O}+\mathrm{H} \cdot \\
& \stackrel{\mathrm{H} \cdot+\mathrm{NO} \longrightarrow(\mathrm{HNO}) \longrightarrow 1 / 2 \mathrm{~N}_{2} \mathrm{O}+1 / 2 \mathrm{H}_{2} \mathrm{O}}{\longrightarrow} \underset{\mathrm{NO}+2 \mathrm{NH}_{3} \longrightarrow 2 \mathrm{~N}_{2}+\mathrm{N}_{2} \mathrm{O}+3 \mathrm{H}_{2} \mathrm{O}}{\longrightarrow}
\end{aligned}
$$

1） $\mathrm{N}_{2}$ への選択率（気相に存在する $\mathrm{N}_{2} /\left(\mathrm{N}_{2}+\mathrm{N}_{2} \mathrm{O}\right)$ で定義）はいずれの条件下でる初期において 大きく時間経過とともに 0.67 という一定值に近うく。

2）生成窒妻中の主成分は $\overline{\mathrm{N}} \mathrm{N}$, 一方, 亜酸化窒素中の主成分は NNO であり, $\bar{N} N O, \bar{N} \bar{N} O$ など は認められなかった。

3） $\mathrm{H}_{2}$ または $\mathrm{CO}$ による NO の還元反応でよく実験結果を説明したレドックス機構はこの系の場 合不適当であった。

$\mathrm{H}_{2}$ または COによる NO の還元反応と対比し, $\mathrm{NH}_{3}$ と NO の反応の場合は Langmuir-Hinshelwood 機構で反応が進行し，ここに提出した機構により， $\mathrm{O}_{2}$ を含むような実際の反応系においても $\mathrm{NH}_{3}$ と NO の反応は優先的に進行して選択的還元反応が行なわれるというこの反応の特徽をよく説明すること ができた。

\section{1 榰言}

大気污染物質として知られる NO を除去する方法として $\mathrm{H}_{2}$, $\mathrm{CO}, \mathrm{NH}_{3}$ などの還元性物質を用いる接触還元法がある。それら の中です $\mathrm{NH}_{8}$ による還元は $\mathrm{NH}_{3}$ が他の二者にくらべ一般的な意 味での還元能力が低いにもかかわらずより低温で反応が進行し， かっ $\mathrm{O}_{2}$ などによる阻害をうけないという特徽のあることが知ら れている3タ)。したがってNOの $\mathrm{NH}_{3}$ による還元俚他の二者とは 異なる反応機構で進行しているように思われる。

著者らは $\mathrm{Fe}_{2} \mathrm{O}_{3}-\mathrm{Al}_{2} \mathrm{O}_{3}$ 上での $\mathrm{H}_{2}$ お よび $\mathrm{CO}$ による NO の還 元はいわゆるレドックス機構で進行することを明らかにしてき だ)。ここでは同一触媒上での NO と $\mathrm{NH}_{8}$ の反応をとりあげ反 応機構を検討し, $\mathrm{NO} と \mathrm{CO}$ または $\mathrm{NO} と \mathrm{H}_{2}$ の反応との機構の 相違を明らかにすることを目的とした。

1）この報文を“一酸化窒素の接触逻元反応(第 4 報)”とする.

2）前報 (第 3 報), 新山浩雄, 飯田 博, 越後谷悦郎, 日化, 1975, 1467.

* 東京工業大学工学部化学工学科, 152 東京都目黑区大岡山

3) M. Shelef, J. T. Kummer, Chem. Eng. Progr., Symp. Ser., 67, n 155, 74(1971).

4) H. C. Anderson, W. J. Green, D. R. Steele, Ind. Eng. Chem., 53, 199(1961).

5）越後谷悦郎，新山浩雄，蛯谷厚応，日化，1974，222.
なおこの反応の機構についてはすでに Shelef らがいくつかの

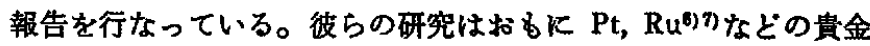
属触媒を用いており，その他 $\mathrm{Cu}$ 触菻名 についても行なっている が，酸化物上での機搆については報告恃少ない。

\section{2 実験}

2.1 触媒

硝酸鉄 (III) $\mathrm{Fe}(\mathrm{NO})_{3}$ 水溶液とアルミナゾル-200(日産化学製) を混合し加温して水分を適当に除いたのち 3 時間混ねいする。こ のあと乾燥し $16 \times 24$ メッシュにふるい分けたすのを空気中 $650^{\circ} \mathrm{C}$ 3 時間焼成した。以下この触媒を $\mathrm{Fe}_{2} \mathrm{O}_{3}-\mathrm{Al}_{2} \mathrm{O}_{3}$ と書く。 $\mathrm{CoO}-$ $\mathrm{Al}_{2} \mathrm{O}_{3}, \mathrm{NiO}-\mathrm{Al}_{2} \mathrm{O}_{3}$ 再同様な調彆法に上り得た。

なお，ここで用いた触媒は既報ら記臷のむのと同じすのであ る。

2.2 反 店

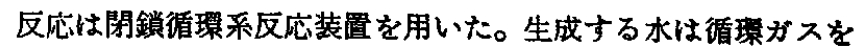
$\mathrm{NaOH}$ 管を通すことにより除去した。反応成縤は系の全王减少，

6) K. Otto, M. Shelef, J. T. Lummer, J. Phys. Chem., 74, 2690(1970).

7) K. Otto, M. Shelef, Z. Phys. Chem. Neue Folge, 85, 308(1973).

8) K. Otto, M. Shelef, J. Phys. Chem., 76, 37(1972). 
組成变化を同時に追跡することにより検討した。系の組成はガス クロマトグラフィーによる分析により $\mathrm{N}_{2}, \mathrm{~N}_{2} \mathrm{O}$, NO 量を求め， それらの值および全压の変化から $\mathrm{NH}_{3}$ の量を計算した。なお反 応活性柱すべて $\mathrm{N}_{2}, \mathrm{~N}_{2} \mathrm{O}$ の生成量または $\mathrm{NO}$ 減少量をるって表 示し, 大きな計算望差を生じ得る $\mathrm{NH}_{3}$ の量は活性表示には用い ない。

反応操作はつぎのようにして行なら。

1） $500^{\circ} \mathrm{C} て ゙ 1$ 時間排気，2） $500^{\circ} \mathrm{C} て ゙ \mathrm{H}_{2}$ とより 1 時間罢元，

3）排気しながら反応温度まで降温，4） 反応開始，5） 反応 温度で 1 時間排気。

2 回目以後は予借還元を行なわず反応温度での排気のみを行な 亏。

\section{3 実験結果および考察}

$\mathrm{NO}$ と $\mathrm{NH}_{3}$ の反応に和ける $\mathrm{Ni}, \mathrm{Co}, \mathrm{Fe}$ 触媒の活性を図 1 に示 す。これらの触媒はさきに報告らした NO の $\mathrm{H}_{2}$ による僄元反応

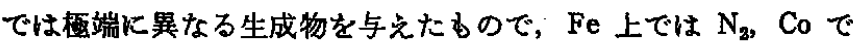
は $\mathrm{N}_{2} \mathrm{O}$ を $\mathrm{Ni}$ では $\mathrm{NH}_{8}$ が主生成物であっだ。しかし NOの $\mathrm{NH}_{8}$ Kよる反応ではこれらいずれの触媒を用いてる反応生成物 に差異は認められなかった。いずれの触媒上でも第 1 回目の活性 は大き く，2回目以後は大略一定の活性を示した。以後は图 1 か ら明らかなようにとくに高活性を示した $\mathrm{Fe}_{2} \mathrm{O}_{3}-\mathrm{Al}_{2} \mathrm{O}_{3}$ 系に括ける 結果を示す。

\section{1 レトックス機構の否定}

ここでいらレドックスとはつぎの一般式で示されるよらなるの である。

$$
\mathrm{R}_{1} \mathrm{O}+\mathrm{M} \longrightarrow \mathrm{R}_{1}+\mathrm{MO}, \mathrm{MO}+\mathrm{R}_{2} \longrightarrow \mathrm{M}+\mathrm{R}_{2} \mathrm{O}
$$

ここで，M性触媒を示す。

すなわち酸素を含む一方の反応物 $\left(\mathrm{R}_{1} \mathrm{O}\right)$ が触媒化酸素を与兄， 一方その酸化された触媒を還元剂 $\left(\mathrm{R}_{2}\right)$ が還元するといらすので ある。とくにここでいらレドックスとは逐次的に還元绪, 酸化剂 が触媒と反応するるのであら，表面上でそれらの反応物同志の直 接的相互作用性ないすのに限定して拉く。 $\mathrm{H}_{2}$ と $\mathrm{NO}, \mathrm{CO}$ と $\mathrm{NO}$ の反応游いずれも上で限定したせまい意味でのレドックス型であ ることが明らかにされた。

もし $\mathrm{NO}$ と $\mathrm{NH}_{3}$ の反応もとのような機棈で進行するとすれば 触蝶と NO, 触媒と $\mathrm{NH}_{3}$ との反応は第 2 の反応物の存在とは無 関保にある程度は(活性点のすべてが酸化または價元されるまで) 進行するはずである。実際に行なった結果 NO と還元触媒の反応 はすみやかに起こるが， 1 回以上 $\mathrm{NO}$ と $\mathrm{NH}_{3}$ の反応便用した 触媒（以下寸でK NOKよる触媒の酸化が終了し表面の酸化状態 が定常になったといら意味で “定常触媒”とよぶ）とNO の反応 はわずかであった。また， $\mathrm{NH}_{3}$ と還元触媒または定常触媒との 反応恃通常の操作温度より高い $300^{\circ} \mathrm{C}$ に执いてすら認められなか った。

\section{$3.2 \mathrm{~N}_{2}$ 選択策に見られる特徽}

NO と $\mathrm{NH}_{\mathrm{z}}$ との初期組成比を $3 / 1,3 / 2,3 / 4,2 / 2,4 / 2,5 / 2$, 反 応温度を $150,200,230^{\circ} \mathrm{C}$ と変化させて反応活性， $\mathrm{N}_{2}$ 選択率の 変化を検討した。結果の一例を図 $2 ， 3$ K示す。これらからとく に $\mathrm{N}_{2}$ 選択率にみられる特徽を以下に列举する。

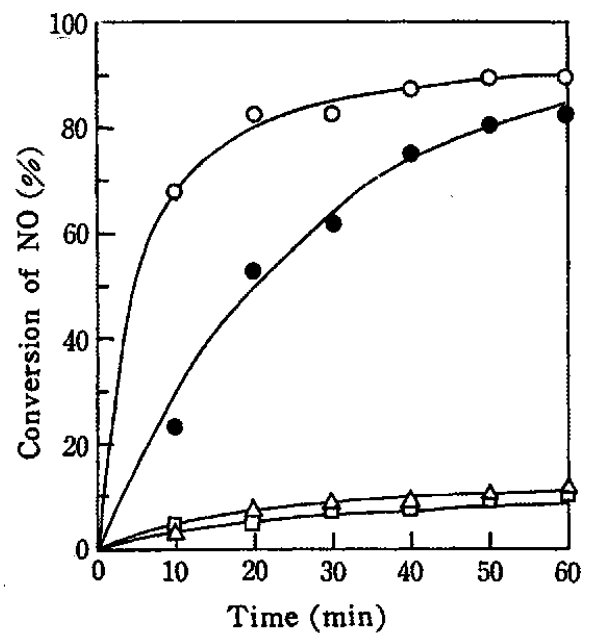

Fig. 1 Activities of prereduced $\mathrm{Fe}_{2} \mathrm{O}_{3}-\mathrm{Al}_{2} \mathrm{O}_{3}$ (O), $\mathrm{CoO}-\mathrm{Al}_{2} \mathrm{O}_{3}(\triangle), \mathrm{NiO}-\mathrm{Al}_{2} \mathrm{O}_{3}(\square)$ and non-reduced (used-cat) $\mathrm{Fe}_{2} \mathrm{O}_{3}-\mathrm{Al}_{2} \mathrm{O}_{3}$ (O) in the reaction of nitrogen oxide with ammonia at $200^{\circ} \mathrm{C}$

$\mathrm{O}: \mathrm{Fe}_{2} \mathrm{O}_{3}-\mathrm{Al}_{2} \mathrm{O}_{3}$ (lst run after reduction),

: $\mathrm{Fe}_{2} \mathrm{O}_{3}-\mathrm{Al}_{2} \mathrm{O}_{3}$ (2 nd run after reduction), $\triangle: \mathrm{CoO}-\mathrm{Al}_{2} \mathrm{O}_{3}, \square: \mathrm{NiO}-\mathrm{Al}_{2} \mathrm{O}_{3}$

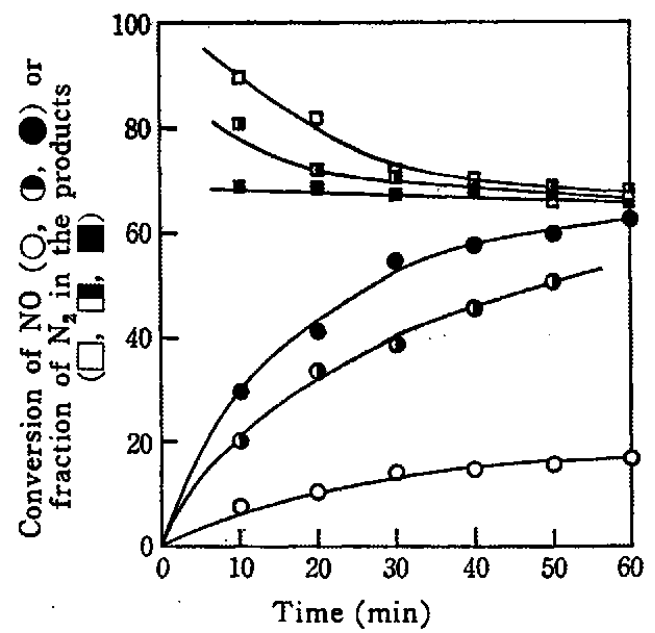

Fig. 2 Conversion of $\mathrm{NO}$ and fraction of $\mathrm{N}_{2}$ in the products against time at various temperature $\bigcirc: 150^{\circ} \mathrm{C}, \quad: 200^{\circ} \mathrm{C}, \bigcirc: 230^{\circ} \mathrm{C}, \square:$ sel $\mathrm{NO} / \mathrm{NH}_{3}=3 / 2$

1） $\mathrm{N}_{2}$ の選択率は初期飞おいて高い。

2）その傾向は低温になるほど顕著である。

3）初期組成，反応温度をかえても最終的化は一定値 $\approx 66 \%$ に 近つく（ただし，後で述べるよ5に高温域で多少滈くな り $70 \%$ 程度の值を示す).

以上に述べた特徵を合理的に説明する反応機構を考えてみる。 いまつぎのような逐次反応を想定してみよう。

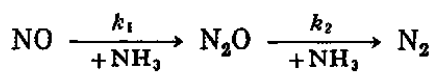

この反応経路はNO の還元反庆においてしばしば仮定され，ある いは確認されている。しかしこの反応経路で進行するとした場合 $\mathrm{N}_{2}$ 選护率は反応時間とともに增加する。これは $\mathrm{N}_{2}$ 選択摔が初 期において高く次第に低下して一定値となる実験結果と明らかに 


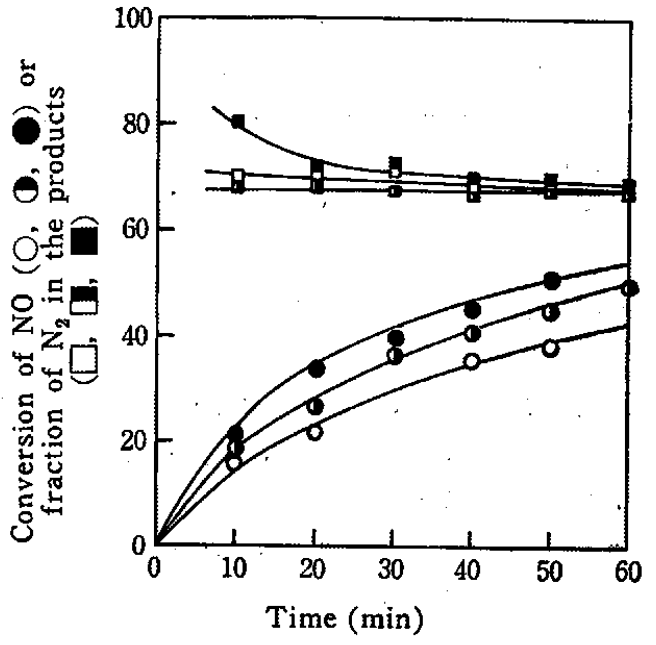

Fig. 3 Conversion of $\mathrm{NO}$ and fraction of $\mathrm{N}_{2}$ in the products against time under various initial pressures at $200^{\circ} \mathrm{C}$

$\mathrm{NO} / \mathrm{NH}_{3}=$

$$
\bigcirc, \square: 3 / 1, O, \square: 5 / 2, \bigcirc, \square: 3 / 2
$$

反する。

つぎ $\mathrm{NO}$ と $\mathrm{NH}_{3}$ より $\mathrm{N}_{2}, \mathrm{~N}_{2} \mathrm{O}$ が平行に, かつおたがいに無 関倸に生成するよらな並列反応 (2)を考えてみよう。<smiles>N#[W]C1C=CC(=[N+]=O)C1[N+](=O)[O-]</smiles>

$r_{1}, r_{2}$ はそれぞれの経路の速度である。

$$
\begin{aligned}
& r_{1}=k_{1} f_{1}\left(P_{\mathrm{NO}}, P_{\mathrm{NH}_{3}}\right) \\
& r_{2}=k_{2} f_{2}\left(P_{\mathrm{NO}}, P_{\mathrm{NH}_{3}}\right)
\end{aligned}
$$

とおく。ここで, $k_{1}, k_{2}$ は速度定数, $P_{\mathrm{NO}}, P_{\mathrm{NH}_{3}}$ はそれぞれ NO および $\mathrm{NH}_{3}$ の分圧， $f_{1} ｆ_{2}$ はそれぞれ吸着など起因する $P_{N O}$ および $P_{\mathrm{NH} 3}$ の関数である。

初期組成，反応温度を变えてる最終的な $\mathrm{N}_{2}$ 選択率が一定にな るためには, $f_{1} \equiv f_{2}$ および $k_{1}, k_{2}$ の活性化エネルギーが等しく なければならない。このようなことはきわめてまれにしか起こり

得ないことであるのでこの説明も否定される。

この反応を合理的に説明するものとしてつぎのような機構を考 える。たたし窒素の由来を明らかにする目的で $\mathrm{NH}_{3}$ の窒素は $\overline{\mathrm{N}}$ と記す。

$$
\begin{aligned}
& \mathrm{NO}+\overline{\mathrm{N}} \mathrm{H}_{3} \longrightarrow \mathrm{NN}+\mathrm{H}_{2} \mathrm{O}+\mathrm{H} \cdot \\
& \cdot \mathrm{H}+\mathrm{NO} \longrightarrow \mathrm{HNO} \\
& 2 \mathrm{HNO} \longrightarrow \mathrm{NNO}+\mathrm{H}_{2} \mathrm{O}
\end{aligned}
$$

$4 \mathrm{NO}+2 \overline{\mathrm{NH}_{3}} \longrightarrow 2 \mathrm{~N} \overline{\mathrm{N}}+\mathrm{N}_{2} \mathrm{O}+3 \mathrm{H}_{2} \mathrm{O}$

この機構が $\mathrm{N}_{2}$ 選択率にみられた特徽を十分満足に説明するこ とは明らかである。すなわち $\mathrm{N}_{2}$ の選択率は初期において高く， （4）（5）の反応を完結したとき量論反応式は（6)で示され，そ のとき選択率は $66.7 \%$ になり，この值は反応機構が変化しない

\begin{tabular}{|c|c|c|c|c|c|c|}
\hline $\begin{array}{l}\text { Run } \\
\text { No. }\end{array}$ & & NN & $\overline{\mathbf{N}} \mathrm{N}$ & NNO & $\bar{N} N O$ & $\frac{\overline{\mathrm{N} N}}{(\mathrm{NNO}+\mathrm{NN})}$ \\
\hline 1 & $\begin{array}{l}\text { Initial }{ }^{a)} \\
\text { Final }^{b)}\end{array}$ & $\begin{array}{l}15.6 \\
24.1\end{array}$ & $\begin{array}{l}52.2 \\
60.0\end{array}$ & $\begin{array}{l}32.2 \\
16.6\end{array}$ & $\begin{array}{l}0 \\
0\end{array}$ & $\begin{array}{l}1.09 \\
1.47\end{array}$ \\
\hline 2 & $\begin{array}{l}\text { Initial } \\
\text { Final }\end{array}$ & $\begin{array}{r}9.1 \\
20.5\end{array}$ & $\begin{array}{l}63.6 \\
70.4\end{array}$ & $\begin{array}{r}27.2 \\
9.1\end{array}$ & $\begin{array}{l}0 \\
0\end{array}$ & $\begin{array}{l}1.75 \\
2.38\end{array}$ \\
\hline 3 & $\begin{array}{l}\text { Initial } \\
\text { Final }\end{array}$ & $\begin{array}{r}8.3 \\
19.0\end{array}$ & $\begin{array}{l}65.0 \\
70.9\end{array}$ & $\begin{array}{l}26.7 \\
10.1\end{array}$ & $\begin{array}{l}0 \\
0\end{array}$ & $\begin{array}{l}1.86 \\
2.44\end{array}$ \\
\hline \multicolumn{7}{|c|}{$\begin{array}{l}\text { Temp.: } 200^{\circ} \mathrm{C} \text {, Initial pressure : } \mathrm{NO}=90 \text { Torr, } \\
{ }^{16} \mathrm{NH}_{3}=50 \text { Torr. }\end{array}$} \\
\hline
\end{tabular}
かぎり反温度, 初期組成に低存しない。

反応系に水を共存させると全体的に活性は拈ちるが $\mathrm{N}_{2}$ 選択率 は初期より一定である。この事实はHNOのような極性物質が水
Table 1 Isotopic composition of the products in the reaction of $\mathrm{NO}+{ }^{16} \mathrm{NH}_{3}$

の存在により水和され表面を動きやすくなり（5）の過程,すなわ ち表面に和ける移動と会合の速度が增するのと解积される。また 高温飞おいて初期から $\mathrm{N}_{2}$ 選択率が一定であるのも(5)の過程の 速度增加として説明されよう。

なおここで提出した機構は Shelef らが Pt 触媒上での NO と ${ }^{15} \mathrm{NH}_{s}$ との反応生成物の同位体組成を説明するために提案した6) あのでありここではそれに対する動力学的支持を与えたことと なる。

\section{$3.3 \mathrm{NO}$ と ${ }^{15} \mathrm{NH}_{3}$ との反応}

上記の機構は同位体によりラベルした ${ }^{15} \mathrm{NH}_{3}$ (以下 $\mathrm{NH}_{8}$ と略 記する）を使用することにより容易に確証することができる。結 果を表 1 に示す。

特徵的な知見を以下に示す。

1）西酸化育素はすべて NNO であり $\bar{N} N O$ はみられない。

2）空素は NN おょび $\bar{N} N$ がみられるが，NN の占める剖合 は run No.が大きくなるとともに減少する.

上記 2) の事実は還元した触媒と NO との間で起こる非触媒的 反応"が(3)から(5)に示される NO と $\mathrm{NH}_{3}$. の触媒的反応に重 畳しているためと理解できよう。

ここで用いた実験装置は図 1,2などに打けるすのよりる容積が 小さく，かつ NO 压る低いことを考虑すれば，1回目の反応では 還元触媒と NO の反応は十分進行せず 2 回目以後すわずかにでは あるが起こっているものと考えられる。熏元触媒と $\mathrm{N}_{2} \mathrm{O}$ との反 応は，NO との反応にくらべて速いことはわかっている。そこで 生した NNO のかなりの部分はさらに還元され $\mathrm{N}_{2}$ になること

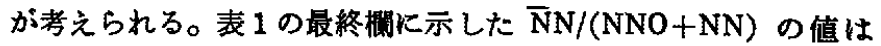
すし還元触媒と NO の反応が無視できるとし, さらに触媒的反応 が(3)〜(5)の機構でのみ進行するとすれば, その值は 2 になる はずである。実祭 run No. が大きくなると2に近ついいていく傾 向がはっきりとらかがえる。

(3)の過程が単一の素反応であるか，あるいは (3-a)，(3-b) のよらに二つの素過程に分割できるのかについては現在のところ 不明である。

$$
\begin{aligned}
& \mathrm{NH}_{3} \longrightarrow \mathrm{NH}_{2 \mathrm{ad}}+\mathrm{H}_{\mathrm{ad}} \\
& \mathrm{NO}_{\mathrm{ad}}+\mathrm{NH}_{2 \mathrm{ad}} \longrightarrow \mathrm{N}_{2}+\mathrm{H}_{2} \mathrm{O}
\end{aligned}
$$

しかし、 $\mathrm{Fe}-\mathrm{Al}_{2} \mathrm{O}_{3} か ゙ \mathrm{Ni}-\mathrm{Al}_{2} \mathrm{O}_{3}, \mathrm{Co}-\mathrm{Al}_{2} \mathrm{O}_{3}$ より極端に活性の高 い事実, 扰よび $\mathrm{Fe}-\mathrm{Al}_{2} \mathrm{O}_{8}$ がフンモニフの分解㧍よび合成に高活 性であり，それ強いアンモニフの解離睃着能婂せられている

9） 反応ガスと触媒との反応のことでこここでは 2 NO+逃元 サイト— $\mathrm{N}_{2}+$ 酸化サイト の反応をさす。 
事実を考え合わせると， $\mathrm{Fe}-\mathrm{Al}_{2} \mathrm{O}_{8}$ 系何ついては (3-a)，(3-b)の ように分割する方が適当かるしれない。これらの点については今 後倹討してゆきたい。

最後に $\mathrm{NH}_{3}$ Kよる還元が選択的還元であること，すなわち系 K $\mathrm{O}_{2}$ が共存する場合でる選択的飞 $\mathrm{NO}$ と $\mathrm{NH}_{3}$ の反応が進行す ることについての一つの可能な説明を提案しょう。 $\mathrm{H}_{2}, \mathrm{CO} に よ$ る NO の還元は NO を触媒住対する酸化刘， $\mathrm{H}_{2}$ ， CO を触媒に対 する還元戍とするせまい意味での逐次的レドックスであることが 明らかにされた2)10)。このよらな機構では NOKよる触媒の酸化 は，強い酸化肪である $\mathrm{O}_{2}$ による触媒の酸化と競争的である。こ

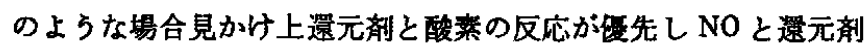
との反応は非選択的になることは容易に理解される。るしる $\mathrm{NH}_{8}$ によるNO の接触還元反応る $\mathrm{H}_{2}, \mathrm{CO}$ の場合と同様にレドックス
機構で進行するとすれば， $\mathrm{O}_{2}$ が存在したときは $\mathrm{O}_{2} か ゙$ NO のか わりに触某の酸化侍与し反応が非選択的となる。しかし $\mathrm{NH}_{8}$ による僄元反応忙 Langmuir-Hinshelwood 型の反応機構で進行 すると考学られるので $\mathrm{O}_{2}$ が存在しても， $\mathrm{O}_{2}$ が触媒上で $\mathrm{NH}_{3}$ と 反応したりするようなことがなければ $\mathrm{NO}$ と $\mathrm{NH}_{3}$ の反応は選択 的に進行することとなる。事実このような低温では $\mathrm{NH}_{3}$ と $\mathrm{O}_{2}$ と の反応が進行しないことがこの触媒上で確かめられている。

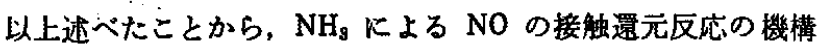
は $\mathrm{H}_{2}, \mathrm{CO}$ による NO の還元機構と異なり， $\mathrm{O}_{2}$ が存在する実際

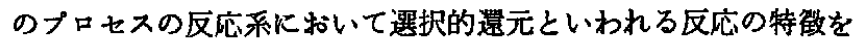
よく説明することができた。

本研究費の一部恃文部省科学研究费補助金特定研究 “罢境保全 のための化学反応制御”によった。ここに記して謝意を表する。

10）蛯谷厚志，新山浩雄，越後谷说郎，日化，1974，1185.

\author{
Mechanism for the Catalytic Reduction of NO with \\ $\mathrm{NH}_{3}$ over $\mathrm{Fe}_{2} \mathrm{O}_{3}-\mathrm{Al}_{2} \mathrm{O}_{3}{ }^{\dagger}$ \\ Hiroo Niyama, Tomohiro Ookawa and Etsuro Echigoya \\ Department of Chemical Engineering, Tokyo Institute of \\ Technology; Ookayama, Meguro-ku, Tokyo 152 Japan
}

The reaction mechanism for the $\mathrm{NO}+\mathrm{NH}_{\mathbf{s}}$ was studied by means of closed circulation system. The products were $\mathrm{N}_{2}$ and $\mathrm{N}_{2} \mathrm{O}$, under the conditions studied. Isotopically labelled ammonia, $\overline{\mathrm{N}} \mathrm{H}_{s}$, was also used in order to clarify nitogen-atom sources in the products. It was concluded that the reaction proceeds through the following successive steps.

$$
\begin{aligned}
& \mathrm{NO}+\mathrm{NH}_{3} \longrightarrow \mathrm{N}_{2}+\mathrm{H}_{2} \mathrm{O}+\mathrm{H} \cdot \\
& . \mathrm{H}+\mathrm{NO} \longrightarrow \text { (HNO) } \longrightarrow 1 / 2 \mathrm{~N}_{2} \mathrm{O}+1 / 2 \mathrm{H}_{2} \mathrm{O} \\
& \stackrel{4 \mathrm{NO}+2 \mathrm{NH}_{3} \longrightarrow 2 \mathrm{~N}_{2}+\mathrm{N}_{2} \mathrm{O}+3 \mathrm{H}_{2} \mathrm{O}}{\longrightarrow}
\end{aligned}
$$

This mechanism was led from the following results.

1) The selectivity to $\mathrm{N}_{2}$, defined as $\mathrm{N}_{2} /\left(\mathrm{N}_{2}+\mathrm{N}_{2} \mathrm{O}\right)$ in the gas phase, was high in the initial stage of reaction and then approached a constant value of 0.67 under the conditions studied. 2) The main product in nitrogen was $\bar{N} \mathrm{~N}$, while dinitrogen oxide was $\mathrm{N}_{2} \mathrm{O}$. 3) The redox scheme which was valid in the catalytic reduction of $\mathrm{NO}$ with $\mathrm{H}_{2}$ or $\mathrm{CO}$ was found to be unappropriate.

The reaction mechanism (1) and (2) proposed here, compared with our proceeding studies concerning $\mathrm{NO}+\mathrm{H}_{2}$ or $\mathrm{NO}+\mathrm{CO}$ reaction, well explained the characteristics of $\mathrm{NO}+\mathrm{NH}_{3}$ reaction, that is, selective reduction in a practical system containing significant amount of oxygen.

$\dagger$ Catalytic Reduction of Nitrogen Oxide. IV. 